\title{
CEMENT BRICKS BASED ON SHREDDED AUTOMOBILE TIRES
}

\author{
Nour Waheed ${ }^{1}$, Ibrahim M. I brahim ${ }^{1}$, M. A. $\operatorname{Radwan}^{1}$, M. A. Sadek ${ }^{1}$, Hany A. Elazab ${ }^{1,2 *}$ \\ ${ }^{1}$ Department of Chemical Engineering, The British University in Egypt, El-Shorouk City, Cairo, Egypt. \\ ${ }^{2}$ Nanotechnology Research Centre (NTRC), the British University in Egypt (BUE), El-Sherouk City, Suez Desert \\ Road, Cairo, 11837, Egypt. \\ * Corresponding Author:_elazabha@ vcu.edu
}

\begin{abstract}
The essential target of this is to make good qualified bricks with economic background and to have several uses than ordinary brick that is utilized in construction of homes or any building. From these useful properties of those blocks are acoustic segregation and thermal insulation also with recovery of many wastes that don't be benefit from them; create from them jobs to be reused and to make brick economically wise and to be applied for example the insulation. From those squandering; are the shredded used tires after being used and it can't be used anymore. It was cleared that the ultimate percent that cement brick can withstand was $10 \%$. After the test of acoustic and temperature measurements by EXTECH instrument, explored that automobile tire addition makes a decline in sound and temperature surrounding also decreased it. Which has a good effect on cement brick by enhancing the insulation of sound and thermal where sound insulation from $55 \mathrm{db}$ to $42 \mathrm{db}$ and make thermal insulation where temperature before is $37{ }^{\circ} \mathrm{C}$ and then after addition of $10 \%$ which the best percent that cement brick can withstand; temperature becomes $26{ }^{\circ} \mathrm{C}$ which make an insulation of about $11{ }^{\circ} \mathrm{C}$. In addition, that shredded used tires decreases cost of cement standard brick by $7.6 \%$.
\end{abstract}

Key Words: Automobile tires, Pollution, Cement bricks.

\section{PROBLEM DEFINITION AND OBJECTIVES}

Nowadays, everything should be developed from the idea of economic as much as possible by having the same quality. So, make economic analysis for concrete blocks by getting rid of the wastes also to decrease cost and to prevent environment from any risks or damages. From the hazardous problems that solid waste of tires made is leaching; which means that when tires begins to crumble a mechanical failure happens it begins to leach carcinogenic substances that make cancer. If those wastes of automobile tires are in contact with the soil, first it doesn't affect the soil but after leaching and then moving the tire to transport to another location this will lead to make the soil becomes toxic and also the groundwater becomes toxic and can be poisoning for any animal is in contact with this toxic soil and water which is very harmful.

The target of this research is to determine the ratios and maximum percent of automobile tire that concrete brick can take to make good insulation for acoustic and also make heat segregation without decreasing the compression strength of the ordinary brick without adding any additives like tire.

\section{RESEARCH METHODOLOGY}

The Strategy of this research as shown in the following steps:

1. Elaboration of powder automobile tire.

2. Drying the tire to get rid of any humidity.

3. Make compression test to determine the maximum percent of tire can be withstanding.

4. Gauge the following properties:

i. Compression strength.

ii. Thermal segregation.

iii. Sound insulation by Extech 5-in- 1 environmental meter.

\section{SCIENTIFIC BACKGROUND}

Ignoring solids squandering threaten soils and water ground which makes environmental troubles. The automobile tires one form of this category of wastes that should be get rid of them; because it doesn't dissolve handy through a long time and create these problems. [122]However, that cement bricks are from the essential bricks in buildings for structure than clay bricks; because, clay bricks make issues for lands; gives not good 
characteristics that are required in construction like low flexibility, retraction, minimum stretchy intensity, shattering connected with stiffness. [23-44] So, there are surveys done to implement the low properties of concrete blocks by adding those wastes to be increased and from those wastes is the rubber or named by used car tires. [4562]

First year of recovery of rubber wastes was in 1991 to be used on roads which confirms The Intermodal Surface Transportation Efficiency Act which is icon is (ISTEA), The first accepted percent of adding the automobile tire was $5 \%$ and not decreasing than this percent; and then from year 1991 to 1997; they declared that it is possible to be used to $20 \%$ to increase properties; but, above this percent begins to deteriorate those properties in cement bricks. [63-74] There are many studies that should be checked after being those rubbers concrete available in the markets and the streets and until now the presence of those sort of blocks don't frequently trade. From those surveys that don't be known until now is the insulation of heat and acoustic. So, in this research this will be discussed in details later in the results and discussion which increase mechanical and environmental problems that are exist. [7482]

In these days, cement bricks are used very much because of the obtainable slits and gravels which are obtain from mountains through transportation and by crushing them to get it; this operation making many problems to the environment. So, nowadays using of automobile tire instead of the stodgy aggregates. When adding the used tire to cement; it doesn't increase the strength whether is for compression or any strength but, it let it the same value of strength. [83-93]

\section{Experimental work}

\subsection{Materials}

\section{- Shredded automobile tire}

Shredded automobile tire is an environmental solid wastes which threaten environment and health and leads to various circumstances so, for this reason all over the world begins to dispose this wastes and regenerated it by using it in many applications to give better properties and to reinforcement mechanical characteristics like thermal and acoustic insulation. First tires go to be cutter in tire cutter then transmits to another equipment called shredded tire and the last final step is transmitted to rubber crusher to be very fine powder automobile tire. And then mixed with cement brick ingredients which are cement, sand, aggregates dolomite and water. To show how does it affect the properties like sound and heat; if it makes changes or not. It is used as a powder with less than 600 microns.

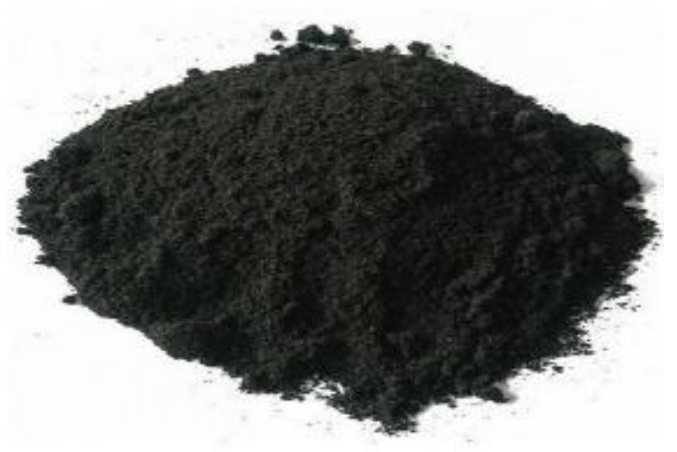

FigURE 1.SHOWS AUTOMOBILE USED TIRES AS A FINE POWDER

\section{- $\quad$ Portland cement 52}

Portland cement type 52 is used as a powder which consists of two essential materials which are clay and limestone and those materials comes from natural.

\section{- Dolomite aggregates}

This type of aggregates is used in the industry of concrete; it is used in the Opeke for concrete industry in Badr city. According to the size of dolomite aggregates, it should be less than or equal to $1 \mathrm{~cm}$ not more than this size.

\section{- Sand}

Rough sand with size particle of 600 microns to enhance the strength of any mixture because it includes many so tiny aggregates that have many advantages in the samples on the view of the compression strength which increases the strength.

\subsection{Apparatus}

\section{- Universal testing machine}

This instrument is very important for testing various matters of each compression strength and also its tensile strength. Actually it has many different usages for testing like bending and hardness for the sample. Sample for this machine should be in the structure of cylinder or to be in a cube form to be tested; this machine is connected to another device software which is computerized to draw the curves of strength and gives the accurate value of force and strength; that sample can withstand before the failure.

\section{- EN-300 5-in-1 Environmental Meter}

This EXTECH instrument with model 5 in 1 because, it measures 5 different variable things like temperature, sound (acoustic), moisture in air, speed of air, and the last parameter is measuring light intensity. This instrument has a smart screen LCD as shown in figure 25 that shows the 
values on this screen. The display of values appears in the opposite direction of the parameter that measures. It contains 6 batteries to be work and getting results, there are also 6 buttons. There is a velocity of air acts like a fan in the bottom used to measure air velocity when function is changed to mode of air velocity also there is a light sensor acts like a lamp to measure the light intensity of the surrounding and also a thermometer to measure temperature. At the top of instrument there is a microphone to measure acoustic sound. This instrument depends on many sensors and each battery is 9 volts. It is an accurate instrument and it is easily to be used, it has a rapid response, and it allows to measure temperature surroundings until to $2372^{\circ} \mathrm{F}\left(1300^{\circ} \mathrm{C}\right)$ which is a very high temperature that can withstand. So, Extech EN-300 has dual main function according to this report which is acoustic sound and this will be measured by microphone on the top and the temperature and this is measures through thermos Ensor inside instrument. (International Organization for Standardization. Acoustics, 2013)

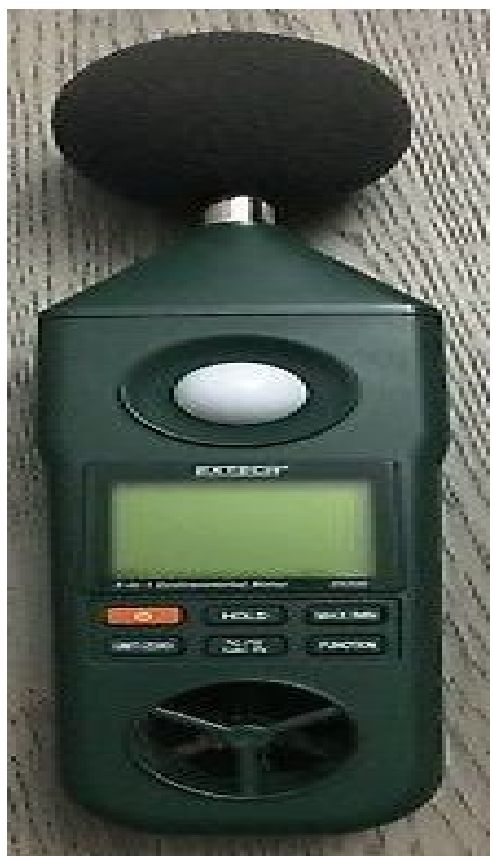

Figure 2. SHOWS EN-300 5 - IN -1 ENVIRONMENTAL METER

\section{Sample preparation}

Add from 70 to $80 \mathrm{~g}$ of cement and it various corresponding to ratios but all masses in the molds equals $430 \mathrm{~g}$, with sand, aggregates, water, with different percentage of powder automobile tire. For samples without aggregates, 70 - 80 gram of cement is fixed with different masses for sand due to various ratios which is $1: 2$, or $1: 4$, or, 1:6. Blend all those ingredients with a uniform high speed motion by a stirring rod. Then add powder automobile tire to the mixture of standard cement sample.
Different samples are made once by aggregates and other without aggregates to determine the better strength. Making a variation in ratios of cement to sand to aggregates for samples with aggregates after adding powder automobile tire. Making a variation in ratios of cement to sand for those samples that without aggregates after adding powder automobile tire. Pour the mixture after blending into the mold. Leave it for 7 days to dry and then go to a furnace with a suitable temperature only to dry if there is water inside sample, it is a check step. Make a compression test to determine the strength. Select the best ratio of cement to sand to aggregates with the best percent of automobile tires to not be under the limit for compression strength. The higher and the appropriate percentage of powder used tire with the best ratio is applied to make sound and thermal test by EXTECH instrument.

\section{RESULTS AND DISCUSSION}

\subsection{Compression test and selecting the highest amount of shredded automobile tire that cement brick can withstand}

TABLe 1ILlustrates THE \% OF ADDED SHREDDED AUTOMOBILE TIRE WITH AGGREGATES

\begin{tabular}{c|c}
\hline $\begin{array}{c}\text { \% of added } \\
\text { shredded } \\
\text { automobile } \\
\text { tire }\end{array}$ & Compression strength (MPa) \\
\hline $\mathbf{1 0} \%$ & automobile tire \\
\hline $\mathbf{8 \%}$ & 2.472 \\
\hline $\mathbf{5 \%}$ & 3 \\
\hline $\mathbf{3} \%$ & 6.7 \\
\hline
\end{tabular}

TABLE 2 ILlustrates THE $\%$ OF ADDED SHREDDED AUTOMOBILE TIRE WITH AGGREGATES

\begin{tabular}{|c|c|}
\hline $\begin{array}{c}\text { \% of added } \\
\text { shredded } \\
\text { automobile } \\
\text { tire }\end{array}$ & $\begin{array}{c}\text { Compression strength (MPa) } \\
\text { Coment brick based on cement \& sand } \\
\text { only }\end{array}$ \\
\hline $\mathbf{8} \%$ & 1.7 \\
\hline $\mathbf{5 \%}$ & 1.75 \\
\hline $\mathbf{3} \%$ & 2.6 \\
\hline
\end{tabular}




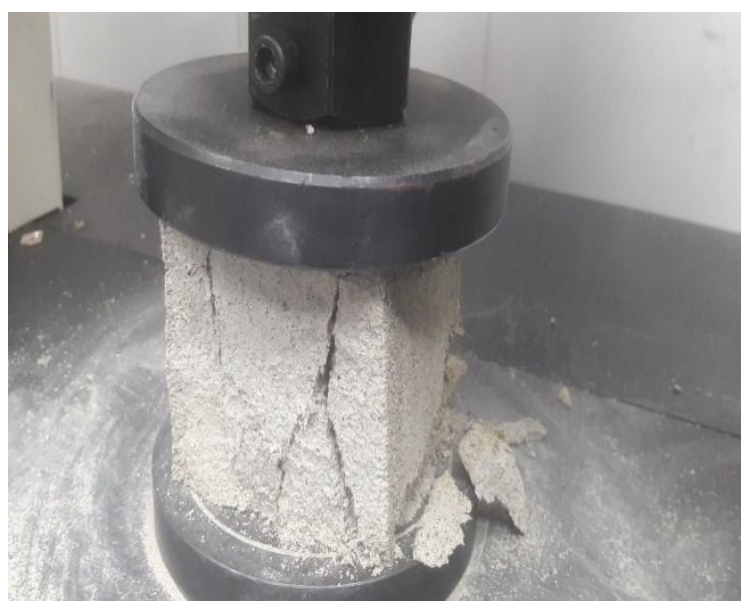

FigURE 3SHOWS CEMENT BRICK WITH POWDER USED TIRE AFTER COMPRESSION TEST

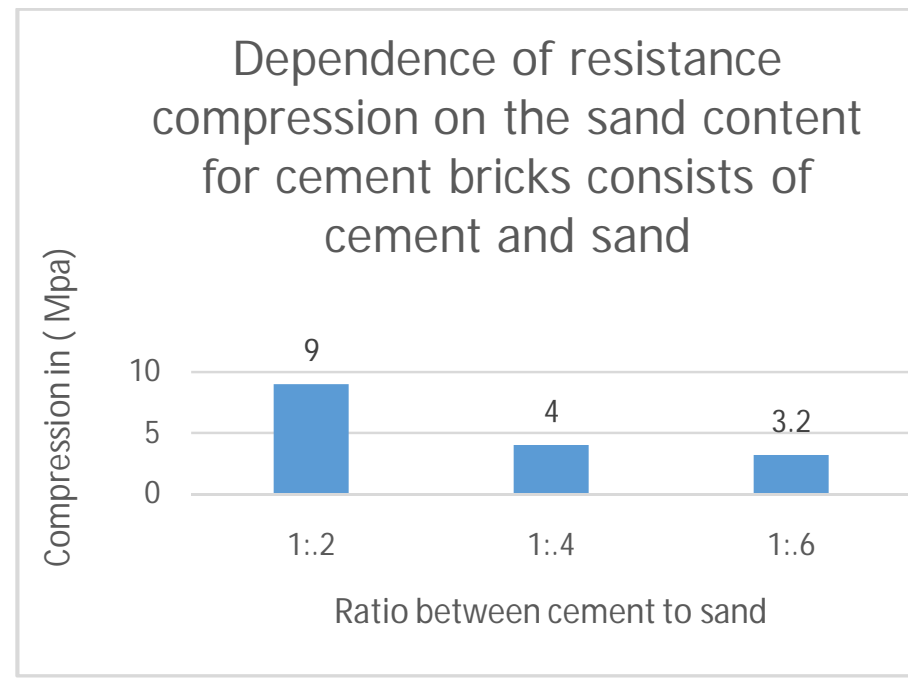

Figure 4 SHOWS THE RESISTANCE OF COMPRESSION WITH DIFFERENT RATIOS OF SAND

It was cleared that by changing ratio of sand relatively to cement first trial is $1: 2$ cement to sand ratio with 0.5 weight of cement added water to make cement brick it gives $9 \mathrm{Mpa}$ which is very high strength; where the Egyptian standard strength is 2 Mpa.To decrease cost and make economic analysis; increase quantity of sand 1:4 cement to sand and water quantity is same doesn't change; after leaving for 7 days and making compression test it gives $4 \mathrm{Mpa}$ which is higher than Egyptian and ASTM also.1:6 gives $3.2 \mathrm{Mpa}$ which exceeds the minimum allowable strength.

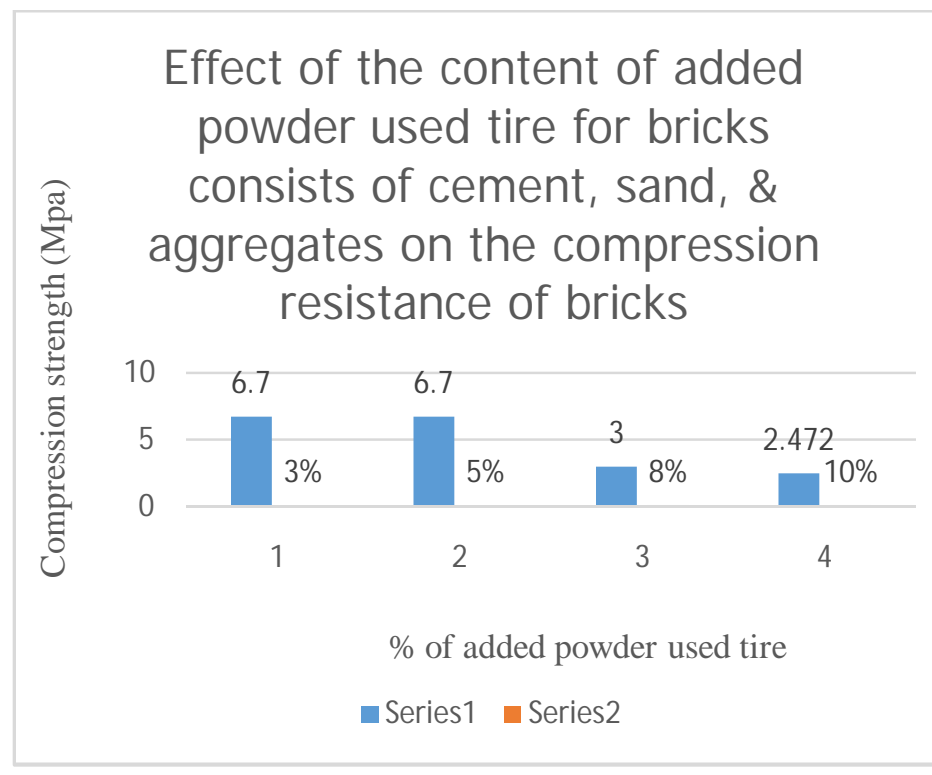

FigURE 5 SHOWS THE RESISTANCE OF COMPRESSION WITH VARIOUS $\%$ OF USED POWDER TIRE

First, all these results that shown in figure 4-1-3 relied on ratio of 1:2:2 cement to sand to aggregates; and by adding powder of used tire by different \%; it is obvious that all percent exceeds the minimum allowable strength which is $2 \mathrm{Mpa}$; where $3 \%, 5 \%, 8 \%$, and $10 \%$ gives 6.7, 6.7, 3, 2.472 Mpa respectively. So, it can be added to $10 \%$ of automobile tire with cement brick to decrease cost and to get rid of its environmental impact, and then make test to determine if it is a good insulator or not according to acoustic and thermal. The ratio of 1:4:6,1:4:2, and 1:4:5 which has a low strength by adding used shredded powder used tires. The outcome that when increasing content of those used shredded tires this decreases strength obviously.

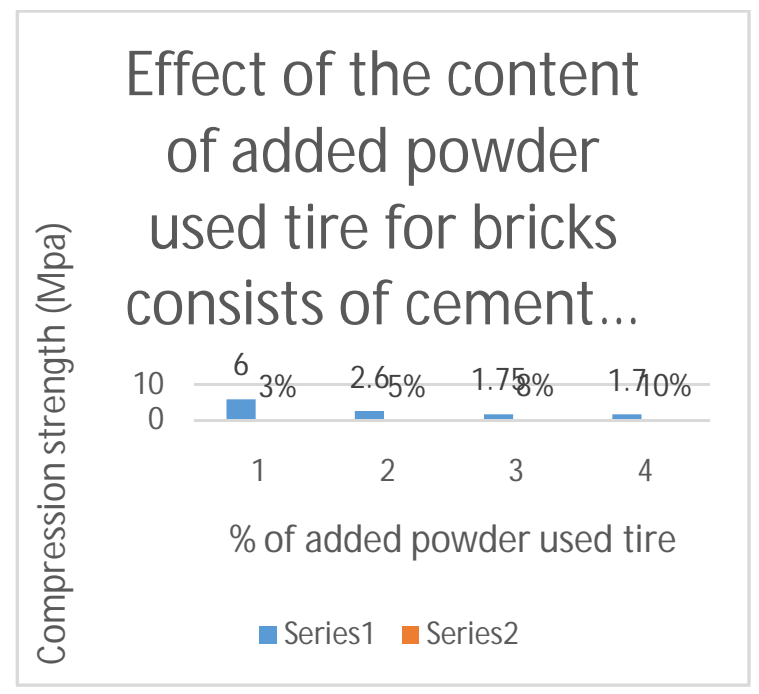

FIGURE 6 SHOWS THE RESISTANCE OF COMPRESSION WITH VARIOUS $\%$ OF USED POWDERTIRE 
It was cleared that as shown in figure 4-1-4 relied on 1:2:2 cement to sand; and by adding powder of used tire by different $\%$; it is obvious that all percent exceeds the minimum allowable strength which is $2 \mathrm{Mpa}$; where $3 \%, 5$ $\%, 8 \%$, and $10 \%$ gives $6,2.6,1.75,1.7$ Mpa respectively. As shown in figure 4-1-3 compared results of strength to figure 4-1-4; It was explored that aggregates increases strength.

\subsection{Thermal and acoustic insulation test}

After selecting the best ratio which is 1:2:2 cement to sand to aggregates; where water is half to cement, it is not the most economic one but at the same time it was the best because the demand that not to decrease the strength of cement brick after adding shredded powder used tire. Then selecting the highest percent that cement brick can withstand a large amount of those waste tires which are 10 $\%$ to make the tests of thermal and acoustic insulation by EN-300 5-in-1 Environmental Meter.

\subsection{Results of thermal and acoustic insulation:}

TABLE 3 ILLUSTRATES EFFECT OF SHREDDED AUTOMOBILE TIRE ADDED TO CEMENT BRICK ON SOUND AND THERMAL INSULATION

\begin{tabular}{lll}
\hline & $\begin{array}{c}\text { Cement } \\
\text { brick }\end{array}$ & $\begin{array}{l}\text { Cement brick after addition } \\
\text { of } 10 \% \text { of shredded tire }\end{array}$ \\
\hline $\begin{array}{l}\text { Acoustic } \\
\text { insulation }\end{array}$ & $\mathbf{5 5} \mathbf{~ d B}$ & $\mathbf{4 2} \mathbf{~ d B}$ \\
\hline $\begin{array}{l}\text { Thermal } \\
\text { insulation }\end{array}$ & $\mathbf{3 7}^{\mathbf{0}} \mathbf{C}$ & $\mathbf{2 6}^{\mathbf{0}} \mathbf{C}$ \\
\end{tabular}

It was observed that from the table above that cement brick with a $10 \%$ of shredded tire is added to prepared sample, has a good effect on it; it improves mechanical properties and make good thermal and sound insulation. First set cement brick build as a room with a seal and walls in a closed room and by EXTECH instrument measuring temperature. Where temperature in closed room with surrounding temperature is $60{ }^{\circ} \mathrm{C}$ after measuring temperature cross through cement standard brick it was 37

\section{CONCLUSION}

To sum up, this research has attained new result through substance that make insulation for sound and also for thermal segregation with a lower cost. By mixing all materials required for making cement brick which are cement, sand, aggregates, and water then adding different percentages of powder used tire to determine and choose the ultimate percent that can cement brick can withstand without lowering the limit of compression strength but at the same time
${ }^{\circ} \mathrm{C}$. For, cement brick room which included the shredded powder used tires and left it for 1 minute it equals $26{ }^{\circ} \mathrm{C}$; which means that make insulation for surrounding from 37 ${ }^{\circ} \mathrm{C}$ to $26{ }^{\circ} \mathrm{C}$ where it insulates and make drop for temperature about $11{ }^{\circ} \mathrm{C}$. Percent reduction of temperature after addition of $10 \%$ of powder used tires $=56.7 \%$ And then by the same instrument which is EXTECH by putting it inside the cement bricks room with tires; it has the ability to measure sound pressure level because it has a microphone in the top of device. In a blocked room set an alarm which induced from it a loud sound or noise; and put instrument inside the cement brick room; left for one minute where alarm is beside the cement brick room and it was found that it is 42 Decibels with surrounding noise level of 62 decibels, and then after repeating this step with the cement brick without any additive with the same alarm and same conditions it was found that the sound measurement equals 55 Decibels. Percent reduction of sound pressure level after addition of $10 \%$ of powder used tires $=32.25 \%$.

\subsection{Cost analysis}

Price of 1000 cement brick with ratio of 1:2:2 = $172 \times 2+$ $86=430$ L.E.

After adding of used shredded powder tires which includes $10 \%$ of cement brick volume, it decreases price of cement brick; Price of 1000 cement bricks with ratio of 1:2:2= $154 \times 2+77+10=395.75$ L.E. So, this means when comparing price of 1000 cement standard brick which has cost of 344 L.E to cost after addition of $10 \%$ of those shredded tires $=318$ L.E; thus decreases cost by $7.6 \%$. Where $\frac{430-397.75}{430} \times 100=7.6 \%$

Lower specific gravity of shredded powder used tires compared to sand this makes cement brick to be more lightweight; thus leading to decrease cost of transportation and carriage; which saving more fuel and saving more cost. Addition of those shredded used tires increases voids in cement brick which decreases its weight.

make a good insulation for heat and sound and lowering cost of the cement brick with disposal of those solid tire wastes. It was found that $10 \%$ of shredded powder used tire was the maximum percentage of those waste that cement brick can take it to not make a decline in its strength so, for this reason after many trials it was the best percentage. Then make two tests once for cement brick without any additives and once with powder used tire with 10 $\%$ where sound and measure temperature to determine if it makes a good insulation or not. Finally, by using an EXTECH instrument which measures another 3 things beside thermal and sound; 
it was explored that it makes a good segregation for heat and sound; where it insulates sound from $55 \mathrm{db}$ to $42 \mathrm{db}$ and also for thermal insulate it insulate heat

\section{REFERENCES}

1. Chen S.T., Synthesis of Pd/Fe3O4 Hybrid Nanocatalysts with Controllable Interface and Enhanced Catalytic Activities for CO Oxidation, Journal of Physical Chemistry C, Vol. 116, pp. 2969-12976, March 2012.

2. Radwan N.R.E., El-Shall M.S., Hassan H.M.A., Synthesis and characterization of nanoparticle $\mathrm{Co3O} 4, \mathrm{CuO}$ and $\mathrm{NiO}$ catalysts prepared by physical and chemical methods to minimize air pollution, Applied Catalysis A: General, Vol. 331, pp. 8-18, August 2007.

3. Wang H.L., Ni(OH)(2) Nanoplates Grown on Graphene as Advanced Electrochemical Pseudocapacitor Materials, Journal of the American Chemical Society, Vol. 132, 21, pp. 7472-7477, February 2010.

4. Wang W.W., Zhu Y.J., Ruan M.L., Microwave-assisted synthesis and magnetic property of magnetite and hematite nanoparticles, Journal of Nanoparticle Research, Vol. 9, 3, pp. 419-426, April 2007.

5. Elazab H., Microwave-assisted synthesis of Pd nanoparticles supported on $\mathrm{FeO}, \mathrm{CoO}$, and $\mathrm{Ni}(\mathrm{OH})$ nanoplates and catalysis application for CO oxidation, Journal of Nanoparticle Research, Vol. 16, 7, pp. 1-11, November 2014.

6. Mankarious R.A., et al., Bulletproof vests/shields prepared from composite material based on strong polyamide fibers and epoxy resin, Journal of Engineering and Applied Sciences, Vol. 12, 10, pp. 2697-2701, May 2017.

7. Mohsen W., Sadek M.A., Elazab H.A., Green synthesis of copper oxide nanoparticles in aqueous medium as a potential efficient catalyst for catalysis applications, International Journal of Applied Engineering Research, Vol. 12, 24, pp. 14927-14930, July 2017.

8. Mostafa A.R., Omar H.A.-S., Hany A.E., Preparation of Hydrogel Based on Acryl Amide and Investigation of Different Factors Affecting Rate and Amount of Absorbed Water, Agricultural Sciences, Vol. 8, pp. 2-11, June 2017.

9. Radwan M.A., et al., Mechanical characteristics for different composite materials based on commercial epoxy resins and different fillers, Journal of Engineering and where temperature reduces from $37{ }^{\circ} \mathrm{C}$ to $26{ }^{\circ} \mathrm{C}$. After analysing cost, it is obvious thatcost reduces compared to cement brick by $7.6 \%$ Applied Sciences, Vol. 12, 5, pp. 1179-1185, May 2017.

10. Andrade A.L., Catalytic Effect of Magnetic Nanoparticles Over the $\mathbf{H}(2) \mathbf{O}(2)$ Decomposition Reaction, Journal of Nanoscience and Nanotechnology, Vol. 9, 6, pp. 3695-3699, June 2009.

11. Kustov A.L., CO methanation over supported bimetallic Ni-Fe catalysts: From computational studies towards catalyst optimization, Applied Catalysis a-General, Vol. 320, pp. 98-104, November 2007.

12. Lohitharn N., Goodwin J.G., Impact of $\mathbf{C r}$, Mn and $\mathrm{Zr}$ addition on Fe Fischer-Tropsch synthesis catalysis: Investigation at the active site level using SSITKA, Journal of Catalysis, Vol. 257, 1, pp. 142-151, August 2008.

13. Moreau F., Bond G.C., CO oxidation activity of gold catalysts supported on various oxides and their improvement by inclusion of an iron component, Catalysis Today, Vol. 114, 4, pp. 362-368, October 2006.

14. Sarkari M., Fischer-Tropsch synthesis: Development of kinetic expression for a solgel Fe-Ni/A12O3 catalyst, Fuel Processing Technology, Vol. 97, pp. 130-139, April 2012.

15. Elazab H., The Effect of Graphene on Catalytic Performance of Palladium Nanoparticles Decorated with FeO, CoO, and Ni (OH): Potential Efficient Catalysts Used for Suzuki Cross-Coupling, Catalysis Letters, Vol. 147, 6, pp. 1510-1522, July 2017.

16. Elazab H.A., The continuous synthesis of Pd supported on Fe3O4 nanoparticles: A highly effective and magnetic catalyst for CO oxidation, Green Processing and Synthesis, Vol. 6, 4, pp. 413-424, May 2017.

17. Elazab H.A., Sadek M.A., El-Idreesy T.T., Microwave-assisted synthesis of palladium nanoparticles supported on copper oxide in aqueous medium as an efficient catalyst for Suzuki cross-coupling reaction, Adsorption Science \& Technology, Vol. 36, pp. 1352-1365, May2018.

18. Elazab H.A., Highly efficient and magnetically recyclable graphene-supported $\mathrm{Pd} / \mathrm{Fe} 304$ nanoparticle catalysts for Suzuki and Heck cross-coupling reactions, Applied Catalysis A: General, Vol. 491, pp. 58-69, February 2015.

19. Hirvi J.T., et al., CO oxidation on PdO surfaces, Journal of Chemical Physics, Vol. 133, pp. 8-14, August 2010. 
20. Iglesias-Juez A., Nanoparticulate Pd Supported Catalysts: Size-Dependent Formation of $\operatorname{Pd}(I) / \operatorname{Pd}(0)$ and Their Role in CO Elimination, Journal of the American Chemical Society, Vol. 133, 12, pp. 4484-4489, March 2011.

21. Ivanova A.S., Metal-support interactions in $\mathrm{Pt} / \mathrm{Al} 2 \mathrm{O3}$ and Pd/Al2O3 catalysts for $\mathrm{CO}$ oxidation, Applied Catalysis B-Environmental, Vol. 97, 1-2, pp. 57-71, April 2010.

22. Kim H.Y., Henkelman G., CO Oxidation at the Interface between Doped $\mathrm{CeO} 2$ and Supported Au Nanoclusters, Journal of Physical Chemistry Letters, Vol. 3, 16, pp. 21942199, January 2012.

23. Chattopadhyay K., Dey R., Ranu B.C., Shapedependent catalytic activity of copper oxidesupported Pd(0) nanoparticles for Suzuki and cyanation reactions, Tetrahedron Letters: International Organ for the Rapid Publication of Preliminary Communications in Organic Chemistry, Vol. 50, 26. pp. 3164-3167, December 2009.

24. Hoseini S.J., Modification of palladium-copper thin film by reduced graphene oxide or platinum as catalyst for Suzuki-Miyaura reactions, Applied Organometallic Chemistry, Vol. 31, pp. 5-12, March 2017.

25. Hosseini-Sarvari M., Razmi Z., Palladium Supported on Zinc Oxide Nanoparticles as Efficient Heterogeneous Catalyst for Suzuki Miyaura and Hiyama Reactions under Normal Laboratory Conditions, Helvetica Chimica Acta, Vol. 98, 6, pp. 805-818, April 2015.

26. Nasrollahzadeh M., Ehsani A., Jaleh B., Preparation of carbon supported CuPd nanoparticles as novel heterogeneous catalysts for the reduction of nitroarenes and the phosphine-free Suzuki Miyaura coupling reaction, New Journal of Chemistry, Vol. 39, 2, pp. 1148-1153, February 2015.

27. Nasrollahzadeh M., Palladium nanoparticles supported on copper oxide as an efficient and recyclable catalyst for carbon(sp2) carbon(sp2) cross-coupling reaction, Materials Research Bulletin, Vol. 68, pp. 150-154, April 2013.

28. Mandali P.K., Chand D.K., Palladium nanoparticles catalyzed Suzuki cross-coupling reactions in ambient conditions, Catalysis Communications, Vol. 31, pp.16-20, November 2016.

29. Wang Y., CuO Nanorods-Decorated Reduced Graphene Oxide Nanocatalysts for Catalytic
Oxidation of CO, Catalysts, Vol. 6, 12, pp. 214220, September 2016.

30. Igarashi H., Uchida H., Watanabe M., Mordenite-supported noble metal catalysts for selective oxidation of carbon monoxide in a reformed gas, Chemistry Letters, Vol. 11, pp. 1262-1263, October 2000.

31. Liu W.H., Fleming S., Lairson B.M., Reduced intergranular magnetic coupling in $\mathrm{Pd} / \mathrm{Co}$ multilayers, Journal of Applied Physics, Vol. 79, 7, pp. 3651-3655, May 1996.

32. Luo J.Y., Mesoporous $\mathrm{Co}(3) \mathrm{O}(4)-\mathrm{CeO}(2)$ and $\mathrm{Pd} / \mathrm{Co}(3) \mathrm{O}(4)-\mathrm{CeO}(2)$ catalysts: Synthesis, characterization and mechanistic study of their catalytic properties for low-temperature CO oxidation, Journal of Catalysis, Vol. 254, 2, pp. 310-324, June 2008.

33. Pavlova S.N., The influence of support on the low-temperature activity of $\mathrm{Pd}$ in the reaction of CO oxidationonKinetics and mechanism of the reaction, Journal of Catalysis, Vol. 161, 2, pp. 517-523, May 1996.

34. Diyarbakir S.M., Can H., Metin Ã.n., Reduced Graphene Oxide-Supported CuPd Alloy Nanoparticles as Efficient Catalysts for the Sonogashira Cross-Coupling Reactions, Acs Applied Materials \& Interfaces, Vol. 7, 5, pp. 3199-3206, March 2015.

35. Feng Y.-S., et al., ChemInform Abstract: PdCu Nanoparticles Supported on Graphene: An Efficient and Recyclable Catalyst for Reduction of Nitroarenes, ChemInform, Vol. 46, pp. 4-12, August 2015.

36. Feng Y.-S., et al., PdCu nanoparticles supported on graphene: an efficient and recyclable catalyst for reduction of nitroarenes, Tetrahedron, Vol. 70, 36, pp. 61006105, May 2014.

37. Liu Y., et al., Ultrasensitive electrochemical immunosensor for SCCA detection based on ternary $\mathbf{P t} / \mathbf{P d C u}$ nanocube anchored on three-dimensional graphene framework for signal amplification, Biosensors \& Bioelectronics, Vol. 79, pp. 71-78, July 2016.

38. Shafaei Douk A., Saravani H., Noroozifar M., Novel fabrication of $\mathrm{PdCu}$ nanostructures decorated on graphene as excellent electrocatalyst toward ethanol oxidation, International Journal of Hydrogen Energy, Vol. 42, 22, pp. 15149-15159, August 2017.

39. Hany A. Elazab, Investigation of Microwaveassisted Synthesis of Palladium Nanoparticles Supported on $\mathrm{Fe}_{3} \mathrm{O}_{4}$ as an Efficient Recyclable Magnetic Catalysts for Suzuki Cross Coupling, The Canadian Journal of Chemical 
Engineering, Vol. 96, 12, pp. 250-261, January 2019.

40. Hany A. Elazab,Laser Vaporization and Controlled Condensation (LVCC) of Graphene supported $\mathrm{Pd} / \mathrm{Fe}_{3} \mathrm{O}_{4}$ Nanoparticles as an Efficient Magnetic Catalysts for Suzuki Cross - Coupling, Biointerface Research in Applied Chemistry, Vol. 8, 3, pp. 3314 - 3318, August 2018.

41. Hany A. Elazab, The catalytic Activity of Copper Oxide Nanoparticles towards Carbon Monoxide Oxidation Catalysis: Microwave Assisted Synthesis Approach, Biointerface Research in Applied Chemistry, Vol. 8, 3, pp. 3278 - 3281, June 2018.

42. M. A. Radwan, Omar Al-Sweasy, M. A. Sadek, Hany A. Elazab, Investigating the Agricultural Applications of Acryl Amide based Hydrogel, International Journal of Engineering and Technology(UAE), Vol. 7, 4.29, pp. 168-171, April 2018.

43. Fatma Zakaria, M. A. Radwan, M. A. Sadek, Hany A. Elazab, Insulating material based on shredded used tires and inexpensive polymers for different roofs, International Journal of Engineering and Technology(UAE), Vol. 7, 4, pp. 1983-1988, June 2018.

44. Reem Nasser, M. A. Radwan, M. A. Sadek, Hany A. Elazab, Preparation of insulating material based on rice straw and inexpensive polymers for different roofs, International Journal of Engineering and Technology(UAE), Vol. 7, 4, pp. 1989-1994, June 2018.

45. Mostafa Ghobashy, Mamdouh Gadallah, Tamer T. El-Idreesy, M. A. Sadek, Hany A. Elazab, Kinetic Study of Hydrolysis of Ethyl Acetate using Caustic Soda, International Journal of Engineering and Technology(UAE), Vol. 7, 4, pp. 1995-1999, June 2018.

46. Nourhan Sherif Samir, Mostafa A. Radwan, M. A. Sadek, Hany A. Elazab, Preparation and Characterization of Bullet-Proof Vests Based on Polyamide Fibers, International Journal of Engineering and Technology(UAE), Vol. 7, 3, pp. 1290-1294, May 2018.

47. Basant Ashraf, Mostafa A. Radwan, M. A. Sadek, Hany A. Elazab, Preparation and Characterization of Decorative and Heat Insulating Floor Tiles for Buildings Roofs, International Journal of Engineering and Technology (UAE), Vol. 7, 3, pp. 1295-1298, May 2018.

48. Mandali P.K., Chand D.K., Palladium nanoparticles catalyzed Suzuki cross-coupling reactions in ambient conditions, Catalysis
Communications, Vol. 31, 5, pp. 16-20, October 2016.

49. Wang Y., CuO Nanorods-Decorated Reduced Graphene Oxide Nanocatalysts for Catalytic Oxidation of CO, Catalysts, Vol. 6, 12, pp. 214223, April 2016.

50. Pavlova S.N., The influence of support on the low-temperature activity of $\mathrm{Pd}$ in the reaction of $\mathrm{CO}$ oxidation on Kinetics and mechanism of the reaction, Journal of Catalysis, Vol. 161, 2, pp. 517-523, July 1996.

51. Diyarbakir S.M., Can H., Metin Ã.n., Reduced Graphene Oxide-Supported CuPd Alloy Nanoparticles as Efficient Catalysts for the Sonogashira Cross-Coupling Reactions, Acs Applied Materials \& Interfaces, Vol. 7, 5, pp. 3199-3206, June 2015.

52. M. A. Radwan, Mohamed Adel Rashad, M. A. Sadek, Hany A. Elazab, Synthesis, Characterization and Selected Application of Chitosan Coated Magnetic Iron Oxide Nanoparticles, Journal of Chemical Technology and Metallurgy, Vol. 54, 2, pp. 303-310, June 2019.

53. Hosam H. Abdelhady, Hany A. Elazab, Emad M. Ewais, Mohamed Saber, Mohamed S. El-Deab, Efficient Catalytic Production of Biodiesel Using Nano-Sized Sugarbeet Agro-Industrial waste, Fuel, Vol. 261, pp. 116481, February 2020.

54. Hany A. Elazab, M. A. Sadek, Tamer T. ElIdreesy, Facile Synthesis of Reduced Graphene Oxide-Supported $\quad \mathrm{Pd} / \mathrm{CuO}$ Nanoparticles as an Efficient Catalyst for Cross-Coupling Reactions, Journal of Chemical Technology and Metallurgy, Vol. 54, 5, pp. 934946, August 2019.

55. Hany A. Elazab, Tamer T. El-Idreesy, Polyvinylpyrrolidone - Reduced Graphene Oxide - Pd Nanoparticles as an Efficient Nanocomposite for Catalysis Applications in Cross-Coupling Reactions, Bulletin of Chemical Reaction Engineering and Catalysis, Vol. 14, 3, pp. 490-501, December 2019.

56. Hany A. Elazab, Ali R. Siamaki, B. Frank Gupton, M. Samy El-Shall, Pd-Fe $\mathbf{O}_{3} \mathrm{O}_{4} / \mathbf{R G O : ~ a ~}$ Highly Active and Magnetically Recyclable Catalyst for Suzuki Cross Coupling Reaction using a Microfluidic Flow Reactor, Bulletin of Chemical Reaction Engineering and Catalysis, Vol. 14, 3, pp. 478-489, December 2019.

57. Hany A. Elazab, M. A. Radwan, Tamer T. ElIdreesy, Facile microwave-assisted synthetic approach to palladium nanoparticles supported on copper oxide as an efficient catalyst for Heck cross-coupling reactions, 
International Journal of Nanoscience, Vol. 18, 5, pp. 1850032, June 2019.

58. Hany A. Elazab, S. A. Hassan, M. A. Radwan, M. A. Sadek, Microwave-assisted Synthesis of Graphene supported Hexagonal Magnetite for Applications in Catalysis, International Journal of Innovative Technology and Exploring Engineering (IJITEE), Vol. 8, 12, 5511-5513, 2019.

59. Hany A. Elazab, M. A. Radwan, M. A. Sadek, Hydrothermal Synthesis of Palladium nanoparticles supported on $\mathrm{Fe}_{3} \mathrm{O}_{4}$ Nanoparticles: an Efficient Magnetic Catalysts for CO Oxidation, International Journal of Innovative Technology and Exploring Engineering (IJITEE), Vol. 8, 12, pp. 2792-2794, May 2019.

60. Tarek M. Aboul-Fotouh, Sherif K. Ibrahim, M. A. Sadek, Hany A. Elazab, High Octane Number Gasoline-Ether Blend, International Journal of Innovative Technology and Exploring Engineering (IJITEE), Vol. 8, 9, pp. 732-739, March 2019.

61. Tarek M. Aboul-Fotouh, Islam Alaa, M. A. Sadek, Hany A. Elazab, Physico-Chemical Characteristics of Ethanol-Diesel Blend Fuel, International Journal of Innovative Technology and Exploring Engineering (IJITEE), Vol. 8, 9, pp. 740-747, February 2019.

62. Hany A. Elazab, M. M. Seleet, Said M. A. Hassanein, M. A. Radwan, M. A. Sadek, Synthesis and Characterization of Dinitro Pentamethylene Tetramine (DPT), Journal of Advanced Research in Dynamical and Control System, Vol. 11, 5S, pp. 310-318, August 2019.

63. Hany A. Elazab, M. M. Seleet, Said M. A. Hassanein, M. A. Radwan, M. A. Sadek, Followup and Kinetic Model Selection of Dinitro Pentamethylene Tetramine (DPT), International Journal of Innovative Technology and Exploring Engineering (IJITEE), Vol. 8, 8, pp. 2862-2866, October 2019.

64. Hany A. Elazab, Mamdouh Gadall, M. A. Sadek, Tamer T. El-Idreesy, Hydrothermal Synthesis of Graphene supported $\mathrm{Pd} / \mathrm{Fe}_{3} \mathrm{O}_{4}$ Nanoparticles as an Efficient Magnetic Catalysts for Suzuki Cross - Coupling, Biointerface Research in Applied Chemistry, Vol. 9, 2, pp. 3906-3911, March 2019.

65. Hany A. Elazab, M. M. Seleet, Said M. A. Hassanein, M. A. Radwan, M. A. Sadek, 3,7Dinitro-1,3,5,7-Tetraazabicyclo[3,3,1]Nonane (DPT): An Important Intermediate in the Synthesis Route of one of the Most Powerful Energetic Materials (RDX/HMX), International Journal of Innovative Technology and Exploring Engineering (IJITEE), Vol. 8, 452, pp. 88-95, April 2019.

66. Hany A. Elazab, Tamer T. El-Idreesy, Optimization of the Catalytic Performance of $\mathrm{Pd} / \mathrm{Fe}_{3} \mathrm{O}_{4}$ Nanoparticles Prepared via Microwave-assisted Synthesis for Pharmaceutical and Catalysis Applications, Biointerface Research in Applied Chemistry, Vol. 9, 1, pp. 3794-3799, July 2019.

67. Hany A. Elazab, Yousab G. Remiz, Mostafa A. Radwan, M. A. Sadek, Synthesis and Characterization of Chitosan Based Catalyst for Catalysis Applications, International Journal of Advanced Trends in Computer Science and Engineering (IJATCSE), Volume 9, Issue 1, PP. 521-527, February 2020.

68. Hassaan M. Shehata, Dalia A. Ali, Islam M. AlAkraa, Hoda A. Elsawy, Hany A. Elazab, Development of novel adsorbent for industrial wastewater treatment, International Journal of Advanced Trends in Computer Science and Engineering (IJATCSE), Volume 9, Issue 1, PP. 704712, February 2020.

69. M. H. El Dewaik, Mamdouh Gadalla, M. A. Sadek, Hany A. Elazab, Mathematica as an Efficient Tool to Optimize the Kinetic Study of Ethyl Acetate Hydrolysis, International Journal of Advanced Trends in Computer Science and Engineering (IJATCSE), Volume 9, Issue 1, PP. 691697, February 2020. 